\title{
PENGARUH PENAMBAHAN BUBUK ARANG KAYU PADA TANAH LEMPUNG TERHADAP NILAI INDEKS PLASTISITAS DAN NILAI CBR
}

\author{
Arpina pahrida ${ }^{1}$, suradji Gandi ${ }^{2}$ dan Fatma Sarie ${ }^{3}$ \\ ${ }^{123}$ Program Studi Teknik Sipil, Fakultas Teknik, Universitas Palangka Raya, \\ E-mailaArpinapahrida96@gmail.com ${ }^{1}$, suradjigandi_ir@jts.upr.ac.id², \\ fatmasarie@jts.upr.ac.id ${ }^{3}$, dan $^{3} /$ HP.+6282158081257 ${ }^{1}$
}

\begin{abstract}
ABSTRAK
Tanah berperan di setiap pekerjaan teknik sipil. Hampir semua bangunan dibuat di atas atau di bawah permukaan tanah. Tanah lempung yang memiliki perilaku lunak, namun tidak juga cair. Kondisi tanah ini dijadikan tanah dasar dari sebuah bangunan struktur sangat tidak kondusif, karena tanah lempung dipengaruhi oleh kadar air yang terkandung pada tanah. Pemanfaatan tanah dengan sifat demikian menyebabkan kegagalan pada kontruksi. metode yang digunakan yaitu pada penelitian ini stabilisasi, dengan menambahkan 2\% 4\% 6\% bubuk arang kayu, dengan peremeraman 3 hari dan 7 hari, yang ditinjau pada penelitian ini adalah nilai CBR dan Indeks plastisitas, karena bubuk arang kayu dapat memperbaiki sirkulasi air dan udara, serta dapat mengikat karbon, dan dapat mengurangi kembang susut tanah karena sifatny mereduksi indeks plastisitas tanah. Dari hasil penelitian yang dilakukan di laboratorium sifat fisik tanah asli didapatakan AASHTO sebagai tanah berlempung kelompok A-6 (6) dan USCS sebagai tanah lempung anorganik dengan plastisitas rendah sampai dengan sedang, tanah termasuk kelompok CL. Nilai Indeks Plastisitas menurun setelah di tambahkan bubuk arang kayu. Analisis data menggunakan analisis varian menyatakan bahwa penambahan bubuk arang kayu memberikan pengaruh terhadap nilai CBR perbaikan tanah dasar. Untuk tanah asli dengan kadar air optimum tanpa campuran nilai CBR RENCANA sebesar 2,12\%. Untuk tanah campuran dengan kadar air optimum penambahan bubuk arang kayu sebesar $2 \%$, 4\%,6\% dengan masa pemeraman 3 hari didapatkan nilai CBR RENCANA sebesar $3,80 \%, 4,20 \%, 4,80 \%$. Tanah dengan campuran kadar air optimum dan penambahan bubuk arang kayu sebesar 2\%, 4\%, 6\% dengan pemeraman 7 hari didapatkan nilai CBR RENCANA 4,70\%, 5,80\%, 7,00.
\end{abstract}

Kata kunci: CBR, Indeks Plastisitas, Bubuk Arang Kayu.

\begin{abstract}
The soil always plays a role in any civil engineering work. Almost all buildings are built either above or below ground level. Clay that has soft behavior, but it also does liquid. This condition of the soil that makes up the basis of a building structure will be highly unstable, as soil is affected by the water content of the soil. Such traits can lead to failure in construction. The method used in this research is stabilization, Adding wood 2\% 4\% 6\% charcoal powder, by a 3-day and 7-day subsection, reviewed on this study is the value of the CBR and the plasticity index, as the wood's charcoal powder improves water and air circulation, and it can bind carbon, and it can also reduce nutrients to the soil by its properties of the reduction of the soil plasticity index.Based on the results of research conducted on the physical nature of the original soil, AASHTO classified
\end{abstract}


subgrade as clay soils in groups A-6 (4) and USCS classified as inorganic clay soils with low plasticity to moderate soil into CL groups. The value of the plasticity index drops after it is added to the wood dust. analysis using a variant analysis suggests that adding wood powder would have an effect on the $C B R_{D E S I G N}$ valuess for a basic soil repair. To native land with an optimum water level without a CBR test of a plan of 2,12\%. For soil mixed with optimum water adding 2\%, 4\%,6\%. with a 3 days retention of 3,80\%, 4.20\%, 4.80\%. The net of optimum water supply and the adding of fibrillated wood powder of $2 \%, 4 \%, 6 \%$ with a 7 days bond of protection obtained a CBR $R_{D E S I G N}$ values of 4,70\%, 5,80\%, $7.00 \%$.

Keywords: CBR, Plasticity Index, Charcoal Powder

\section{PENDAHULUAN}

\section{Latar Belakang}

Tanah adalah pondasi pendukung suatu bangunan, atau bahan konstruksi dari bangunan itu sendiri seperti tanggul atau bendungan, atau kadang-kadang sebagai sumber penyebab gaya luar pada bangunan, seperti tembok/dinding penahan tanah. Dalam pandangan teknik sipil tanah adalah himpunan mineral, bahan organik dan endapan-endapan yang relatif lepas (loose) yang terletak di atas batu dasar (bedrock) (Hardiyatmo, 2006). Jadi, tanah itu selalu berperan pada setiap pekerjaan teknik sipil. Mengingat hampir semua bangunan dibuat di atas atau di bawah permukaan tanah, maka harus dibuatkan pondasi yang dapat memikul beban bangunan itu atau gaya yang bekerja melalui bangunan itu. Maka dari itu tanah selalu mempunyai peranan yang penting pada suatu lokasi pekerjaan kontruksi.

Tanah lempung yang memiliki perilaku pada tanah dalam keadaan lunak, namun tidak juga dalam keadaan cair. Pada kondisi ini tanah yang dijadikan tanah dasar dari sebuah bangunan struktur akan sangat tidak kondusif sehingga menjadikan bangunan menjadi tidak stabil karena tanah lempung dipengaruhi oleh kadar air yang terkandung pada tanah. Pemanfaatan tanah dengan sifat demikian dapat menyebabkan kegagalan pada kontruksi.

Salah satu metode yang digunakan untuk perbaikan properties tanah tersebut adalah dengan metode stabilisasi, bahan tambah bubuk arang kayu sebagai bahan campuran dalam menstabilisasi tanah, hal ini karena bubuk arang kayu dapat memperbaiki sirkulasi air dan udara, serta dapat mengikat karbon, dan juga dapat mengurangi kembang susut pada tanah karena mempunyai sifat mereduksi indeks plastisitas tanah.

\section{Tujuan Penelitian}

Stabilisasi tanah secara umum merupakan pencampuran tanah dengan bahan tertentu, guna memperbaiki sifat-sifat tanah agar dapat menaikkan kekuatan tanah dan mempertahankan kekuatan geser. Menurut Bowles (1991) beberapa tindakan yang dilakukan untuk menstabilisasikan tanah adalah meningkatkan kerapatan tanah, menambah material yang tidak aktif sehingga meningkatkan kohesi dan atau tahanan gesek yang timbul, menambah bahan untuk menyebabkan perubahan-perubahan kimiawi dan atau fisis pada tanah, menurunkan muka air tanah 
(drainase tanah), dan mengganti tanah yang buruk.

Contoh-contoh penelitian terdahulu ysng dijadikan sebagai acuan dalam penelitian Tugas Akhir adalah sebagai berikut :

1. Tugas Akhir "Stabilisasi Tanah Menggunakan Abu Ampas Tebu"oleh Yunita (2003). Penelitian tentang pengaruh stabilisasi tanah menggunakan abu ampas tebu terhadap nilai CBR. Penelitian tersebut bertujan untuk mengetahui seberapa besar pengaruh perubahan nilai CBR pada tanah lempung.

2. Tugas Akhir "Stabilisasi Tanah Menggunakan Bubuk Arang Kayu"oleh Sengeoris (2016). Penelitian tentang pengaruh penambahan bubuk arang kayu pada stabilisasi. Penelitian tersebut bertujan untuk mengetahui perubahan sifat fisis tanah serta mengetahui pengaruh perubahan nilai CBR setelah ditambah bubuk arang kayu.

3. Tugas Akhir "Stabilisasi Tanah Menggunakan Rotec dan Kapur" oleh Shabirin (2017). Penelitian tentang pengaruh stabilisasi tanah menggunakan Rotec dan Kapur terhadap nilai CBR. Penelitian tersebut bertujan untuk mengetahui seberapa besar pengaruh perubahan nilai CBR pada tanah lempung

\section{Tanah}

\section{TINJAUAN PUSTAKA}

Dalam pandangan teknik sipil, tanah adalah kumpulan dari bagian - bagian yang padat dan tidak terikat antara satu dengan yang lain. Rongga - rongga diantara material tersebut berisi udara dan air. Ikatan antara butiran yang relatif lemah dapat disebabkan oleh karbonat, zat organic, atau oksida - oksida yang mengendap diantara partikel - partikel. Ruang diantara partikel - partikel dapat berisi air, udara, ataupun yang lainnya (Hardiyatmo, 2012).

\section{Tanah Lempung}

Lempung (clay) adalah bagian dari tanah yang sebagian besar terdiri dari partikel mikroskopis dan submikroskopis (tidak dapat dilihat dengan jelas bila hanya dengan mikroskopis biasa) yang berbentuk lempengan-lempengan pipih dan merupakan partikel-pertikel dari mika, mineral-mineral lempung (clay minerals), dan mineral-mineral yang sangat halus lain. Lempung membentuk gumpalan keras saat kering dan lengket apabila basah terkena air dan memiliki sifat elastis yang kuat. Lempung juga menyusut saat kering dan memuai saat basah. Karena perilaku inilah beberapa jenis tanah dapat membentuk kerutan-kerutan atau "pecah-pecah" bila kering.

\section{Batas Konsisten}

Batas cair (LL), didefinisikan sebagai kadar air tanah pada batas antara keadaan cair dan keadaan plastis, yaitu batas atas dari daerah plastis. Batas cair biasanya ditentukan dari uji Casagrande. Kemudian, hubungan kadar air dan jumlah pukulan yang dipadatkan dari hasil pengujian menggunakan alat Casagrande digambarkan dalam grafik semi logaritmik untuk menentukan kadar air pada 25 kali pukulan. Batas plastis (PL), didefinisikan sebagai kadar air tanah pada kedudukan antara daerah plastis dan semi plastis, yaitu persentase kadar air dimana tanah yang berbentuk silinder dengan diameter 3,2 $\mathrm{mm}$ dalam keadaan 
mulai retak ketika digulung. Batas susut (SL), didefiniskan sebagai kadar air pada kedudukan antara daerah semi plastis dan padat, yaitu persentase kadar air dimana pengurangan kadar air selanjutnya tidak mengakibatkan perubahan volume tanah

\section{Indeks Plastisitas}

Indeks plastisitas (PI) merupakan selisih antara nilai batas cair (LL) dan batas plastis (PL). Karena itu, indeks plastisitas menunjukkan nilai keplastisitasan tanahnya. Jika tanah mempunyai PI tinggi, maka tanah mengandung banyak butiran lempung. Jika PI rendah, seperti lanau, sedikit pengurangan kadar air berakibat tanah menjadi kering. Indeks plastisitas (PI) adalah selisi batas cair dan batas plastis.

\section{Stabilisasi Tanah}

Stabilisasi tanah secara umum merupakan pencampuran tanah dengan bahan tertentu, guna memperbaiki sifat-sifat tanah agar dapat menaikkan kekuatan tanah dan mempertahankan kekuatan geser. Menurut Bowles (1991) beberapa tindakan yang dilakukan untuk menstabilisasikan tanah adalah meningkatkan kerapatan tanah, menambah material yang tidak aktif sehingga meningkatkan kohesi dan atau tahanan gesek yang timbul, menambah bahan untuk menyebabkan perubahan-perubahan kimiawi dan atau fisis pada tanah, menurunkan muka air tanah (drainase tanah), dan mengganti tanah yang buruk

\section{Bubuk Arang Kayu Sebagai Stabilisasi}

Bubuk arang kayu dapat memperbaiki sirkulasi air dan udara, serta dapat mengikat karbon, dan juga dapat mengurangi kembang susut pada tanah karena mempunyai sifat mereduksi indeks plastisitas tanah. Hal ini dapat menjadi latar belakang penggunaan bubuk arang kayu sebagai bahan stabilisasi, karena sifat dan unsur kimia yang terkandung pada semua jenis arang pada umumnya terdiri dari bahan penyusun yang sama

\section{Uji CBR (California Bearing Ratio)}

Metode perencanaan perkerasan jalan yang umum dipakai adalah cara-cara empiris dan yang biasa dikenal adalah cara CBR (California Bearing Ratio). Metode ini dikembangkan oleh California State Highway Departement sebagai cara untuk menilai kekuatan tanah dasar jalan. Istilah CBR menunjukkan suatu perbandingan (ratio) antara beban yang diperlukan untuk menekan piston logam (luas penampang 3 sqinch) ke dalam tanah untuk mencapai penurunan (penetrasi) tertentu dengan beban yang diperlukan pada penekanan piston terhadap material batu pecah di California pada penetrasi yang sama (Canonica, 1991).

\section{METODE PENELITIAN}

\section{Lokasi Penelitian}

Penelitian ini menggunakan sampel tanah yang berasal dari Desa Banut Kalanaman, Katingan Hilir, Kabupaten Katingan, Kalimantan Tengah. Studi penelitian ini dilakukan di Laboratorium Mekanika Tanah Jurusan/Program Studi Teknik Sipil Fakultas Teknik Universitas Palangka Raya.

\section{Metode Pengambilan Data}

Pada penelitian ini pengambilan sampel tanah lempung didapatkan dari Desa 
Banut Kalanaman, Katingan Hilir, Kabupaten Katingan, Kalimantan Tengah. Ada dua sampel tanah yang diambil yaitu sampel tanah asli (undisturbed) yaitu tanah yang tidak mengalami perubahan sifat mekaniknya dan sampel tanah terganggu (disturbed) yaitu tanah yang telah terjamah atau sudah tidak alami lagi yang telah terganggu oleh lingkungan luar.

\section{Perencanaan Campuran}

Metode pencampuran tanah asli:

a) Sampel tanah yang telah ditumbuk (butir aslinya tidak pecah) dan lolos saringan No. $4(4,75 \mathrm{~mm})$ lalu dicampur dengan bubuk arang kayu kadar campuran $2 \%, 4 \%$, dan $6 \%$, berat tanah.

b) Lalu dilakukan pemeraman selama 3 hari dan 7 hari untuk pengujian pemadatan dan pengujian CBR.

c) Setelah didapatkan kadar air optimal dari pemadatan lalu dilakukan pengujian CBR.

d) Setelah didapat variasi yang paling optimum, lalu dilakukan analisis data dan pengolahan data.

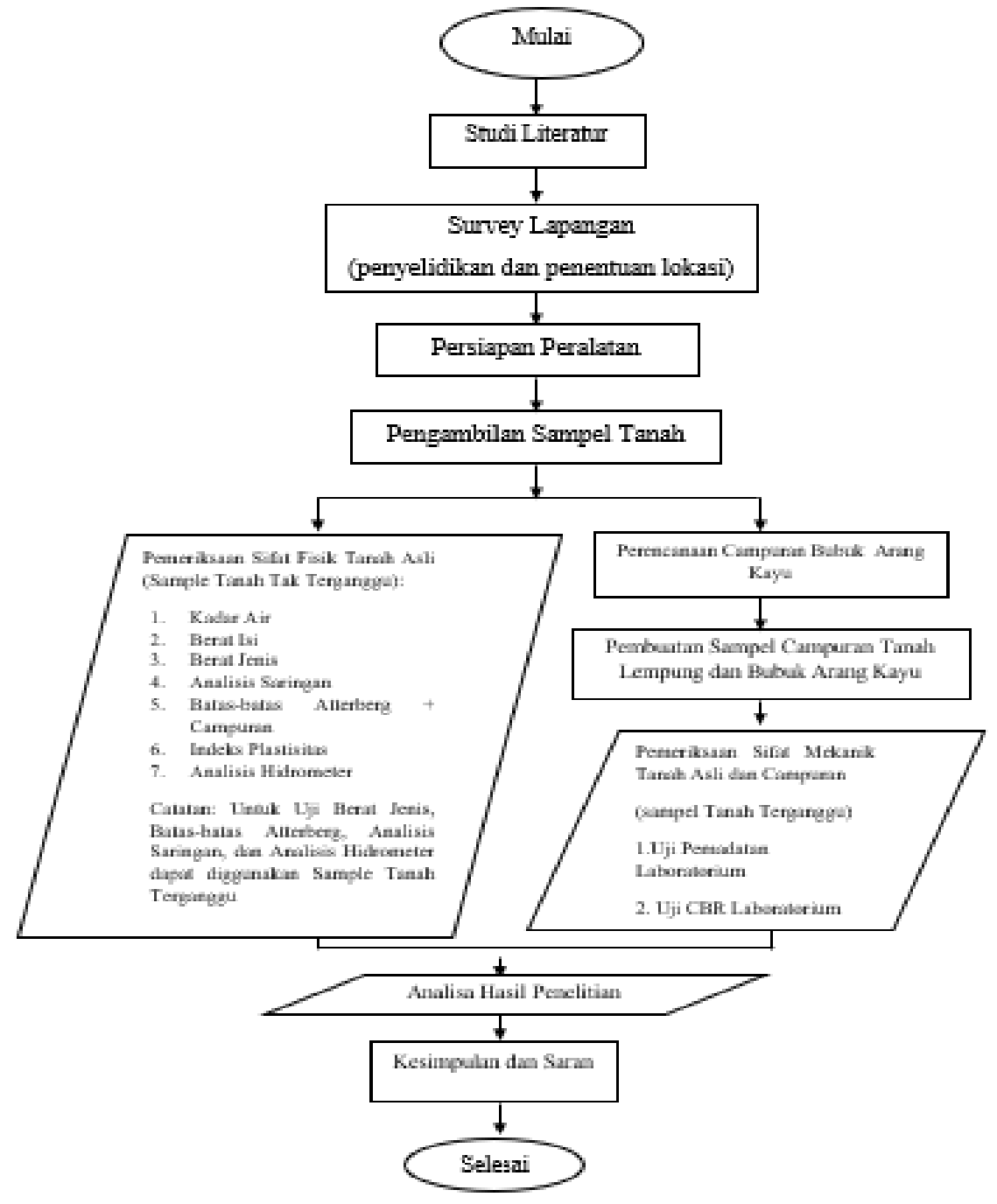

Gambar 1. Bagan Alir Penyusunan Penelitian 


\section{HASIL DAN PEMBAHASAN}

Berdasarkan penelitian yang dilakukan di Laboratorium Mekanika Tanah, Fakultas Teknik Universitas Palangka Raya. Penelitian ini diharapkan dapat memberikan gambaran mengenai karakteristik tanah, yang meliputi sifat fisik dan mekaniknya.

\section{Hasil Pengujian Sifat-Sifat Fisik Tanah}

Tabel 2. Hasil Pemeriksaan Sifat Fisik Tanah

\begin{tabular}{clc}
\hline No. & \multicolumn{1}{c}{ Jenis Pemeriksaan } & $\begin{array}{c}\text { Hasil Pengujian } \\
\text { Rata - rata }\end{array}$ \\
\hline 1. & Kadar Air (Water Content) $\%$ & 37,19 \\
2. & Berat Isi (Density Test) gr/cm ${ }^{3}$ & 1,44 \\
3. & Berat Jenis (Specific Gravity) & 2,75 \\
4. & Batas-Batas Atterberg (\%) & - \\
& a. Batas Cair (Liquid Limit) & 34,00 \\
& b. Batas Plastis (Plastic Limit) & 17,10 \\
& c. Indeks Plastisitas (Plasticity Index) & 16,90 \\
& d. Batas Susut (Shrinkage Limit) & 20,45 \\
5. & Analisis Saringan & - \\
& a. Persentase Berat Tertahan (\%) & 9,50 \\
& b. Persentase Lolos No. 200 (\%) & 52,10 \\
6. & Analisis Hydrometer (\%) & 11,233 \\
\hline
\end{tabular}

Dari sistem klasifikasi tanah menurut AAHSTO tanah tersebut masuk dalam kelompok A-6(6), yaitu tanah jenis berlempung. Kelompok A-6(6) adalah kelompok tanah lempung berlanau.

\begin{tabular}{cccc}
\hline Variasi Campuran & Batas Cair (LL) & Batas Plastis (PL) & PI \\
\hline Tanah Asli 0\% & 34,00 & 17,10 & 16,90 \\
Tanah Asli + Bubuk Arang Kayu 2\% & 33,80 & 17,06 & 16,74 \\
Tanah Asli + Bubuk Arang Kayu 4 \% & 33,60 & 17,05 & 16,54 \\
Tanah Asli + Bubuk Arang Kayu 6\% & 33,40 & 17,04 & 16,36 \\
\hline
\end{tabular}

\section{Pemeriksaan Indeks Platisitas Dengan Penambahan Bubuk Arang Kayu}

Pengujian indeks plastistas (PI) merupakan selisih atara nilai batas cair (LL) dan batas plastis (PL), karena itu, indeks palstisitas menujukan nilai keplastisan tanahnya. 


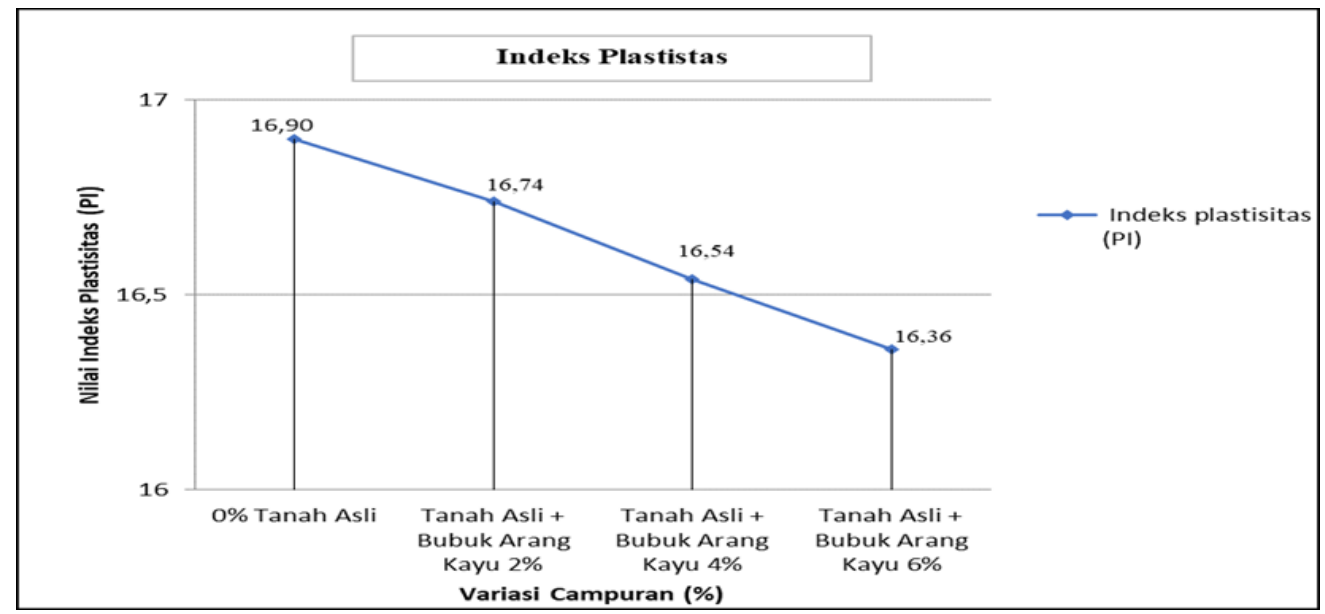

Gambar 2. Grafik Hasil Pengujian Indeks Plastisitas Dengan Campuran

Berdasarkan gravik diatas terjadi penurunan setiap kali ditambahkan campuran bubuk arang kayu, sehinga jika nilai indeks plastisitas (PI) berkurang maka keplastisanny semakin menurun, penambahan bubuk arang kayu mempenggaruhi nilai (PI). Penurunan terbesar terlihat pada penambahan bubuk arang kayu di $6 \%$ nilai indeks plastisitasny (PI )16,36\% dari tanah asli indeks plastisitasny (PI) $16,90 \%$ mengalami penurunan.

\section{Hasil Pengujian Sifat-Sifat Mekanik Tanah}

\section{Uji Pemadatan}

Pengujian pemadatan tanah dilakukan dengan cara pemadatan metode modified yang menggunakan standar ASTM D 698. Pengujian ini dilakukan untuk mendapatkan kadar air optimum dan berat volume kering tanah maksimum yang digunakan sebagai kadar air pada pengujian CBR.

Tabel 3. Rekapitulasi Hasil Pengujian Pemadatan Laboratorium

\begin{tabular}{cccc}
\hline Variasi Campuran & $\begin{array}{c}\text { Waktu } \\
\text { pemeraman }\end{array}$ & $\begin{array}{c}\text { Kadar Air } \\
\text { Optimum } \\
(\%)\end{array}$ & $\begin{array}{c}\text { Kepadatan } \\
\text { Maksimu } \\
\mathrm{m}\left(\mathrm{g} / \mathrm{cm}^{3}\right)\end{array}$ \\
\hline $\begin{array}{c}\text { Tanah asli 0\% } \\
\text { Tanah asli + Bubuk arang kayu 2\% }\end{array}$ & 3 Hari & 22,20 & 1,570 \\
Tanah asli + Bubuk arang kayu 4\% & 3 Hari & 20,17 & 1,596 \\
Tanah asli + Bubuk arang kayu 6\% & 3 Hari & 22,86 & 1,614 \\
Tanah asli + Bubuk arang kayu 2\% & 7 Hari & 22,08 & 1,622 \\
Tanah asli + Bubuk arang kayu 4\% & 7 Hari & 21,21 & 1,630 \\
Tanah asli + Bubuk arang kayu 6\% & 7 Hari & 21,01 & 1,640 \\
\hline
\end{tabular}




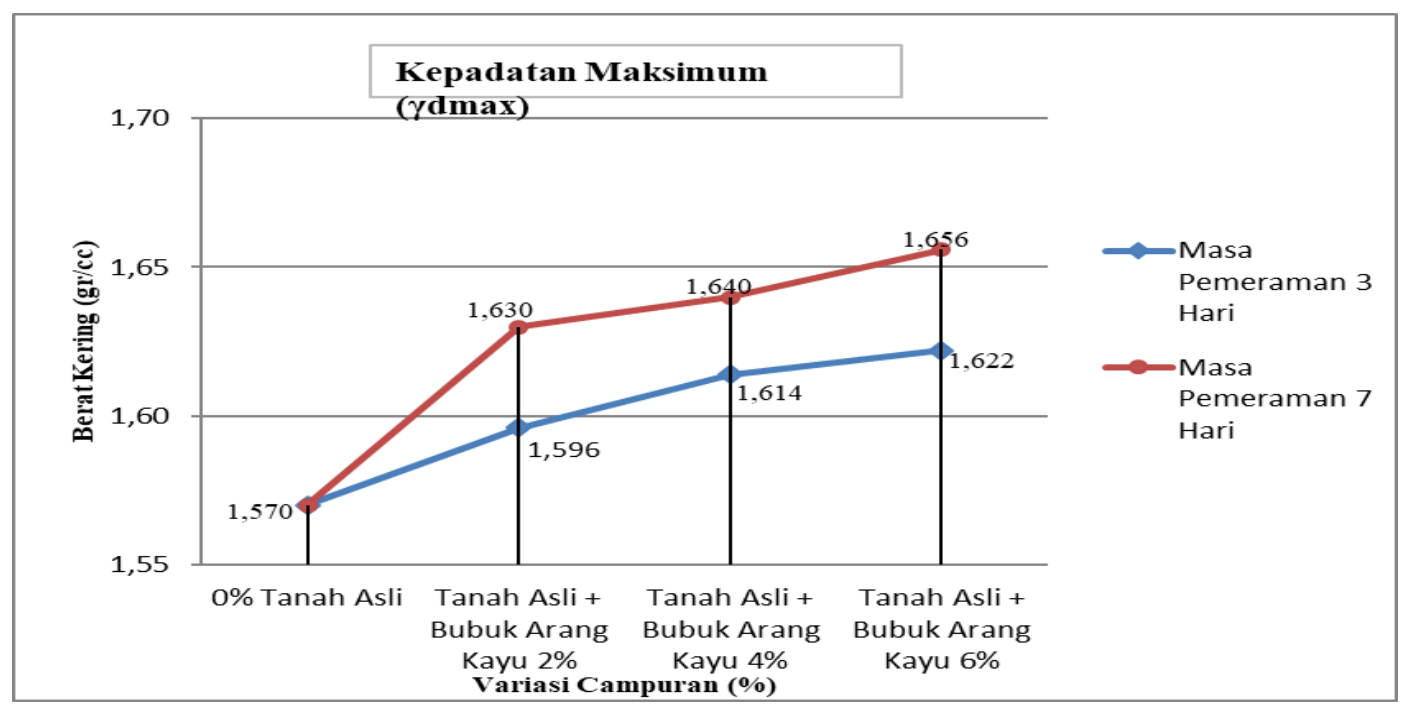

Gambar 3. Grafik Hasil Pengujian Pemadatan Laboratorium

Pada Gambar diatas menunjukan bahwa berat isi kering tanah asli sebesar 1,570 dengan penambahan Bubuk Arang Kayu mendapatkan berat isi kering terbesar menurut grafik di atas terjadi pada penambahan Bubuk Arang Kayu 6\% pada masa pemeraman 7 hari sebesar 1,656 kepadatan maksimumnya. Maka dapat disimpulkan terjadi kenaikan presentase $=5,477 \%$ dari tanah asli ke persentase penambahan Bubuk Arang Kayu 6\%.

\section{Uji CBR}

Pengujian ini dimaksudkan untuk menentukan nilai CBR dengan mengetahui kuat hambatan campuran tanah dengan bubuk arang kayu terhadap penetrasi kadar air optimum dengan waktu pemeraman 3 hari dan 7 hari dengan variasi campuran $2 \% 4 \%$ dan $6 \%$.

Tabel 4. Rekapitulasi Hasil Pengujian CBR Laboratorium

\begin{tabular}{cllc}
\hline Variasi Campuran & \multicolumn{1}{c}{$\begin{array}{c}\text { Waktu } \\
\text { Pemeraman }\end{array}$} & $\begin{array}{c}\text { Berat Kering } \\
95 \%(\mathrm{gr} / \mathrm{cc})\end{array}$ & $\begin{array}{c}\text { Nilai CBR } \\
(\%)\end{array}$ \\
\hline Tanah asli 0\% & 0 hari & 1,492 & $2,12 \%$ \\
Tanah asli + Bubuk arang kayu 2\% & 3 hari & 1,516 & $3,80 \%$ \\
Tanah asli + Bubuk arang kayu 4\% & 3 hari & 1,533 & $4,20 \%$ \\
Tanah asli + Bubuk arang kayu 6\% & 3 hari & 1,541 & $4,80 \%$ \\
Tanah asli + Bubuk arang kayu 2\% & 7 hari & 1,549 & $4,70 \%$ \\
Tanah asli + Bubuk arang kayu 4\% & 7 hari & 1,558 & $5,80 \%$ \\
Tanah asli + Bubuk arang kayu 6\% & 7 hari & 1,573 & $7,00 \%$ \\
\hline
\end{tabular}




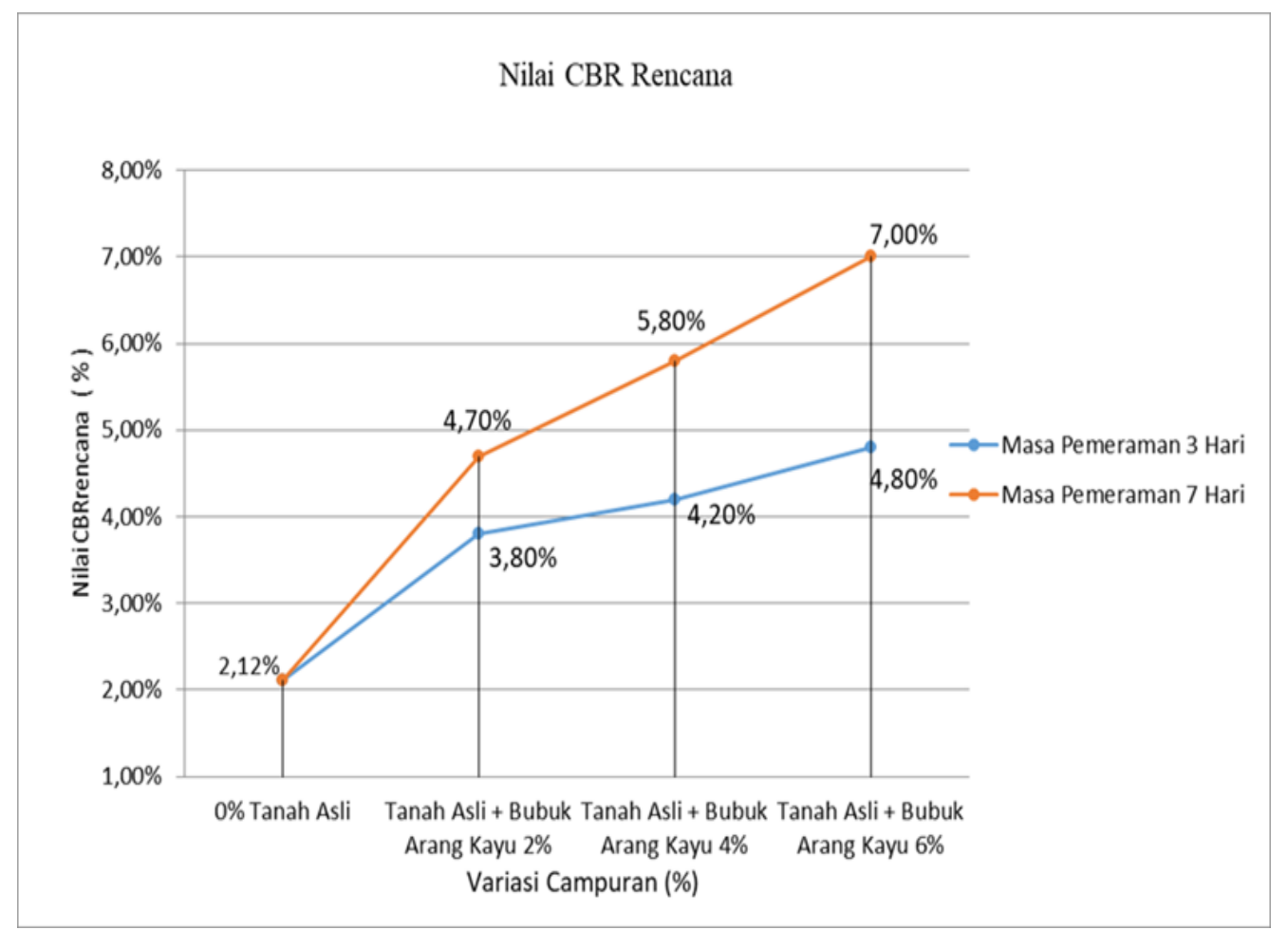

\section{Gambar 4. Grafik Hasil Pengujian CBR Laboratorium}

Pada Gambar 4. nilai CBR tanah asli $=2,12 \%$, dan dengan penambahan bubuk arang kayu didapatkan nilai CBR terbesar padat grafik di atas terjadi pada penambahan bubuk arang kayu 6\% pada masa pemeraman 7 hari sebesar 7,00\% Maka dapat disimpulkan terjadi kenaikan. Setiap penambahan pada varian bubuk arang kayu 2\%, 4\%, 6\%, dan dilakukan pemeraman 3 dan 7 hari nilai CBR mengalami kenaikan dari nilai CBR tanah asli, Nilai CBR campuran $2 \%$ pemeraman 7 hari mengalami kenaikan $121,70 \%$, CBR Campuran $4 \%$ pemeraman 7 hari mengalami kenaikan 173,58\%, CBR Campuran $6 \%$ pemeraman 7 hari, mengalami kenaikan 230,19\%. Maka dapat disimpulkan setiap kali ditambahkan bubuk arang kayu nilainy CBR mengalami kenaikan.

\section{Hubungan Daya Dukung Tanah dengan CBR Rencana}

Daya dukung tanah dasar (DDT) merupakan salah satu parameter yang digunakan dalam nonogram penetapan indeks tebal perkerasan (ITP). Nilai daya dukung tanah dasar didapat dari hari grafik kolerasi CBR tanah dasar terhadap DDT, secara analitis nilai DDT dengan menggunakan persamaan berikut (Sukirman,1999).

DDT $=4,3 \log \mathrm{CBR}+1,7$

Keterangan:

DDT: daya dukung tanah dasar

CBR: nilai CBR tanah dasar

Dengan Maka didapat nilai DDT sebagai berikut :

$\mathrm{DDT}=4,3 \times \log (7,00)+1,7=5,33$ 
JURNAL KACAPURI

JURNAL KEILMUAN TEKNIK SIPIL

Volume 4 Nomor 1 Edisi Juni 2021

\begin{tabular}{|c|c|c|c|}
\hline Variasi Campuran & $\begin{array}{c}\text { Waktu } \\
\text { Pemeraman }\end{array}$ & $\begin{array}{c}\text { Nilai } \\
\text { CBR }_{\text {RENCANA }} \\
(\%)\end{array}$ & $\begin{array}{c}\text { Nilai Daya } \\
\text { Dukung } \\
\text { Tanah Dasar }\end{array}$ \\
\hline Tanah Asli $0 \%$ & 0 Hari & $2,12 \%$ & 3,10 \\
\hline Tanah Asli + Bubuk Arang Kayu 2\% & 3 Hari & $3,80 \%$ & 4,19 \\
\hline Tanah Asli + Bubuk Arang Kayu 4\% & 3 Hari & $4,20 \%$ & 4,38 \\
\hline Tanah Asli + Bubuk Arang Kayu 6\% & 3 Hari & $4,80 \%$ & 4,63 \\
\hline Tanah Asli + Bubuk Arang Kayu 2\% & 7 Hari & $4,70 \%$ & 4,59 \\
\hline Tanah Asli + Bubuk Arang Kayu 4\% & 7 Hari & $5,80 \%$ & 4.98 \\
\hline Tanah Asli + Bubuk Arang Kayu 6\% & 7 Hari & $7,00 \%$ & 5,33 \\
\hline
\end{tabular}

Dari tabel di atas dapat dilihat bahwa nilai daya dukung tanah asli adalah sebesar 3,10 dengan penambahan bubuk arang kayu pemeraman 3 hari meningkat sebesar 4,$19 ; 4,38 ; 4,63$; dan untuk pemeraman 7 hari meningkat sebesar 4,59; 4,98; 5,33; . Nilai daya dukung terbesar terjadi di penambahan bubuk arang kayu 6\% yaitu 5,33. Nilai yang telah didapat selanjutnya akan dilihat pada grafik hubungan antar CBR dengan DDT (daya dukung tanah)

\section{Kesimpulan}

\section{PENUTUP}

Berdasarkan penelitian yang telah dilakukan, maka dapat diambil kesimpulan sebagai berikut:

1. Hasil pengujian sifat - sifat fisik tanah di dapat nilai, $\operatorname{kadar}$ air $(\mathrm{w})=37,19 \%$; berat isi kering $(\mathrm{\gamma d})=1,44 \mathrm{~g} / \mathrm{cm}^{3}$; berat jenis $(\mathrm{Gs})=2,75 \mathrm{~g} / \mathrm{cm}^{3}$; batas - batas Atterberg yaitu $L L=34,00 \% ; P L=17,10 \% ; P I=16,90 \% ; S L=20,45 \%$; analisis saringan persentase lolos saringan no $200=52,10 \%$, analisis hidrometer $=$ 11,233\%. Menurut AASHTO tanah diklasifikasikan tanah berlempung,dalam kelompok A-6 (6), dan menurut USCS tanah diklasifikasikan tanah berlempung anorganik kelompok CL(Tanah Berbutir Halus), dan secara visual tanah berwarna kuning dan bercampur dengan sedikit pasir. Sifat mekanik tanah nilai pemadatan tanah asli $0 \% O M C=22,20 \%, \gamma_{\mathrm{d} \text { max }}=1,570\left(\mathrm{~g} / \mathrm{cm}^{3}\right)$, Penambahan bubuk arang kayu tertinggi komposisi tanah asli 100\% dan bubuk arang kayu $6 \%$ pemeraman 7 hari didapat $O M C=21,01 \%, \gamma_{\mathrm{d} \max }=1,656\left(\mathrm{~g} / \mathrm{cm}^{3}\right)$, maka disimpulkan terjadi kenaikan dari tetinggi di5,477\%

2. Hasil pengujian Indeks Plastisitas dengan campuran bubuk arang kayu terjadi penurunan setiap kali ditambahkan campuran bubuk arang kayu, sehinga jika nilai indeks plastisitas (PI) berkurang maka keplastisanny semakin menurun, penambahan bubuk arang kayu mempenggaruhi nilai (PI). Penurunan terbesar terlihat pada penambahan bubuk arang kayu di $6 \%$ nilai indeks plastisitasny (PI)16,36 dari tanah asli indeks plastisitasny (PI) 16,90 mengalami penurunan. 
3. Hasil pengujian nilai CBR laboratorium:

a. Sampel tanah asli $0 \%$ didapat Nilai $\mathrm{CBR}=2,12 \%$.

b. Nilai CBR tanah asli dan campuran bubuk arang kayu, pemeraman 3 hari, $2 \%$ $\mathrm{CBR}=3,80 \% ; 4 \% \mathrm{CBR}=4,20 \% ; 6 \% \mathrm{CBR}=4,80 \% ; .$. Untuk tanah asli dan campuran bubuk arang kayu, pemeraman 7 hari, $2 \% \mathrm{CBR}=4,70 \%$; $4 \% \mathrm{CBR}$ $=5,80 \% ; 6 \% \mathrm{CBR}=7,00 \%$; Persentase optimum terjadi pada $6 \%$ dengan komposisi tanah asli $100 \%$ + bubuk arang kayu 6\% dan masa pemeraman 7 hari, maka dapat disimpulkan terjadi kenaikan dari tanah asli 2,12\% penambahan bubuk arang kayu yang tertinggi, dengan nilai kenaikan 7,00\%.

\section{Saran}

Berdasarkan hasil dari penelitian dan analisis data yang dilakukan, maka disarankan hal-hal sebagai berikut:

1. Bagi peneliti yang akan datang melakukan penelitian lebih lanjut mengenai pengaruh penambahan bubuk arang kayu dapat menggunakan jenis tanah lain dengan persentase bubuk arang kayu lebih besar agar hasilny lebih optimal dan di lakukan perbandingan degan bahan campuran yang lain.

2. Pada penelitian ini kekurangan uji pendukung lainnya, oleh karena itu perlu penelitian lanjutan dengan melakukan pengujian mekanik tanah lainnya seperti uji triaxial, dan uji geser secara langsung.

3. Untuk melihat kenaikan atau penurunan CBR tanah, sebaiknya dilakukan penambahan umur pemeraman dan dilakukan perendaman.

4. Pemeriksaan pemadatan laboratorium dan pemeriksaan CBR laboratorium dapat menggunakan cara modified agar lebih bervariasi.

\section{DAFTAR PUSTAKA}

1. Bowles, Joseph E. Johan . Helnim. 1991. Sifat-sifat Fisis Geoteknis Tanah (Mekanika Tanah). PT. Erlangga. Jakarta, 151 Halaman.

2. Das, B. M. 1998. Mekanika Tanah (Prinsip-prinsip Rekayasa Geoteknik), Erlangga : Jakarta.

3. Hardiyatmo, Hary Christady. 1992. Mekanika Tanah 1. PT. Gramedia Pustaka Utama . Jakarta.

4. Hardiyatmo, Hary Christady. 2010. Stabilisasi Tanah Untuk Perkerasan Jalan. Gadjah Mada University Press. Yogyakarta.

5. Hardiyatmo, Hary Christady. 2012. Mekanika Tanah 1, Edisi Keenam. Gajah Mada University Press. Yogyakarta. 